\title{
Characterization, Antibacterial and Biological Activities of Phenolic Fraction of Argentinean Red Wines
}

\author{
María G. Stivala ${ }^{1}$, Margarita B. Villecco ${ }^{1}$, Martín Fanzone ${ }^{2}$, Viviana Jofré², María J. Rodríguez- \\ Vaquero ${ }^{1}$ and Pedro Aredes-Fernández ${ }^{1, *}$
}

\author{
${ }^{1}$ Facultad de Bioquímica, Química y Farmacia, Universidad Nacional de Tucumán, Ayacucho 491, Tucumán, Argentina \\ ${ }^{2}$ Laboratorio de Aromas y Sustancias Naturales, Estación Experimental Agropecuaria Mendoza, Instituto Nacional de \\ Tecnología Agropecuaria (INTA), SanMartín 3853, 5507, Luján deCuyo, Mendoza, Argentina
}

\begin{abstract}
For the first time, the qualitative and quantitative characterization of phenolic compounds of lower molecular weight fraction (LMF) were evaluated in commercial Cabernet Sauvignon (CS) and Tannat (T) wines varieties produced in Cafayate, Argentine. The antimicrobial activity against Pediococcus pentosaceus $12 \mathrm{p}$, spoilage wine bacteria as well as the "in vitro" antioxidant and antihypertensive activities were also evaluated. The composition of LMF obtained by liquidliquid extraction with ethyl acetate, determined by HPLC-DAD, showed a total content of phenolic compounds of 229.4 and $311.1 \mathrm{mg} \mathrm{L}^{-1}$ for CS and T wines respectively. Synthetic like-wine media (SWM), pH 4.5 supplemented with LMF at identical concentration of the wine (1X), four (4X) and eight times concentrated (8X), was inoculated with $P$. pentosaceus $12 \mathrm{p}$ at $10^{7} \mathrm{CFU} \mathrm{mL}^{-1}$. Samples were collected at the beginning and final incubation time to determine cell viability in MRS-agar medium and the damage of the cell membrane integrity by electron microscopy observation. In the presence of LMF at $1 \mathrm{X}$ concentration, both fractions diminish growth parameters without cellular damage. In the presence of LMF of $\mathrm{CS}$ and $\mathrm{T}$ wine varieties four and eight times concentrated, cellular death of the microorganism as well as plasmatic membrane disruption was observed. The LMF of both wines analyzed in this study have high antioxidant, radical scavenging and antihypertensive activity. The use of phenolic compounds as potential antimicrobial agents could be an effective additive to controll wine spoilage bacteria, adding on wines beneficial properties to human health.
\end{abstract}

Keywords: Antihypertensive activity, antimicrobial activity, antioxidant activity, Pediococcus pentosaceus, phenolic compounds, wine.

\section{INTRODUCTION}

The principal role of microorganisms involved in the vinification process is to transform sugars from the grape juice in ethanol, reduce the acidity and increase the flavor in the final product. During the vinification process, the lactic acid bacteria (LAB) carry out the malolactic fermentation (MF), process that takes place after the alcoholic fermentation and produce the conversion of L-malic acid into L-lactic acid. This process is suitable to correct the wine acidity values and sometimes contribute to the microbiological stability and enhance the flavor. LAB associated to vinification process that belongs to the genera Lactobacillus, Leuconostoc, Oenococcus, and Pediococcus. The growth of LAB generally takes place after the end of alcoholic fermentation and enables the beginning of the MF. The growth of LAB is influenced by several factors, such as $\mathrm{pH}$ of the medium, $\mathrm{SO}_{2}$ content, temperature, ethanol concentration and the phenolic compounds content of wine. The MF can take place spontaneously or may be induced by

*Address correspondence to this author at the Facultad de Bioquímica, Química y Farmacia, Universidad Nacional de Tucumán, Ayacucho 491, Tucumán, Argentina; Tel: (+54) 381-4247752; Ext. 7067, 4000;

Fax: (+54)381-4248169; E-mail: pedroaredes@ fbqf.unt.edu.ar
LAB starter cultures; whatever the case, the process must be strictly controlled to avoid undesirable bacterial modifications. The alterations associated with the uncontrolled growth of certain strains of Pediococcus pentosaceus include the overproduction of exopolysaccharides and the concomitantly wine alteration, producing the called "Ropy wines", that are unacceptable for consumption. In the wineries is a common practice the use of sulphites after MF to remove spoilage of wine $\mathrm{LAB}$. The levels of $\mathrm{SO}_{2}$ required to slow down the growth and metabolic activity of $\mathrm{LAB}$ oscillate between 10 and $30 \mathrm{mg} \mathrm{L}^{-1}$ of free $\mathrm{SO}_{2}$ for wines with a pH between 3.2 and 3.6, and between 30 to $50 \mathrm{mg} \mathrm{L}^{-1}$ for wines with $\mathrm{pH}$ from 3.5 to 3.7. For wines with higher $\mathrm{pH}$, the dose of free $\mathrm{SO}_{2}$ required can even reach values close to $100 \mathrm{mg} \mathrm{L}^{-1}$. Nevertheless, the utilization of $\mathrm{SO}_{2}$ must be strictly controlled, since that can produce undesirable organoleptic alterations and allergic disorders in susceptible persons. Because of these undesirable effects, new compounds with antimicrobial activity against spoilage bacteria that can substitute totally or at least partially the use of sulphite in the wine industry are required.

Phenolic compound are molecules that are characterized by possessing an aromatic ring with at least one hydroxyl substitution. These compounds, derived from the secondary metabolism of plants are highly distributed in nature and are 
classified in different ways according to the number of carbons in the molecule, the distribution in the nature or their solubility. The term phenolic compounds includes simple phenols, phenolic acids (benzoic or hydroxycinnamic acid derivatives), coumarins, flavonoids, stilbenes, hydrolysable and condensed tannins, lignans, and lignins. The flavonoids can be subdivided into flavonols, flavones, isoflavones, flavanones, anthocyanidins, and flavanols (catechins and proanthocyanidins) [1]. Phenolic compounds have been described previously to have diverse biological effects, such as antioxidant, anticarcinogenic, anti-inflammatory and antimicrobial activities [2]. Fruits, vegetables and beverages derived from them, such as tea, coffee and wine, are the main sources of phenolic compounds in the human diet [3, 4]. Because of their antimicrobial properties of phenolic compounds several authors have proposed their use as natural preservatives and control agents against spoilage microflora during the processing of foods or beverages. With regard to possible application in wine industry, most of the studies conducted at the present are focused in the evaluation of antimicrobial activity against spoilage wine bacteria of pure sole compounds regardless of the fact that in natural environment, the antibacterial effect is affected by total content of phenolic compounds [5]. Recent studies reported the inhibitory effect of different kind of wine phenolic compounds (hydroxybenzoic acids and their derivatives, hydroxycinnamic acids, phenolic alcohols and other related compounds, stilbenes, flavan-3-ols and flavonols) on different $\mathrm{LAB}$ wine isolates [6,7], confirming that phenolic compounds, and particularly phenolic acids, have a great potential in the use as natural preservatives in winemaking. In addition phenolic compounds have shown to interact with wine LAB producing inhibition or stimulation of bacterial growth [6, 7]. The antibacterial activity of phenolic compounds are influenced by the compound's structure and the assayed doses [6]. Furthermore, wine phenolic compounds are related to different beneficial effects on human health associated with moderate wine consumption, especially in relation to cardiovascular diseases [8].

The aim of this study was to characterize in a qualitative and quantitative way the phenolic compounds of lower molecular weight fraction isolated from commercial Cabernet Sauvignon and Tannat wines varieties produced in Cafayate, Argentine, and evaluate the antimicrobial effect of this fraction against Pediococcus pentosaceus 12p, a spoilage wine LAB. Additionally the antihypertensive and antioxidant properties of the phenolic compounds were also evaluated.

\section{MATERIALS AND METHODS}

\subsection{Samples}

Two different red wine varietals produced in Cafayate, Salta, Argentina were obtained directly from wine stores. The utilized wines correspond to Cabernet Sauvignon (CS) and Tannat (T) varieties produced in the 2010 vintage. Wines were stored in darkness at $15-18^{\circ} \mathrm{C}$, and each wine bottle was opened immediately before the assays.

\subsection{Isolation of Wine Phenolic Compounds Fraction}

The low molecular weight fraction of phenolic compounds (LMF) was isolated by a liquid/liquid extraction method. Extraction method was performed on $750 \mathrm{~mL}$ of wine according to procedures reported by Ghiselli, Nardini, Baldiand Scaccini [9] with slight modifications. Ethanol was previously removed by vacuum distillation. An aliquot of $150 \mathrm{~mL}$ of the dealcholized wine $(\mathrm{pH} 2.0)$ was extracted with ethyl acetate (three times with $100 \mathrm{~mL}$ of ethyl acetate each time). The organic fractions were combined, dehydrated with $2.5 \mathrm{~g}$ sodium sulfate anhydrous, and evaporated to dryness under a gentle nitrogen gas stream at $35^{\circ} \mathrm{C}$.

\subsection{HPLC Analysis and Identification}

The solid residue was dissolved in $2 \mathrm{~mL}$ of a solution of methanol/water $(1: 1 \mathrm{v} / \mathrm{v})$, filtered through a $0.45 \mu \mathrm{m}$ pore size nylon membrane, and then injected in the Perkin-Elmer Series 200 High-performance liquid chromatograph (HPLCDAD; PerkinElmer, Shelton, CT). Separation was performed on a reversed phase Nova-Pak C18 column $(300 \mathrm{~mm} \times 3.9 \mathrm{~mm}$ I.D., $4 \mu \mathrm{m}$; Waters Corp., Milford, MA) at $25{ }^{\circ} \mathrm{C}$ according to the method previously reported by Fanzone, Zamora, Jofre, Assof, Gómez Cordovés and Peña Neira [10]. Diode array detection was performed by scanning from 210 to 360 $\mathrm{nm}$ with an acquisition speed of $1 \mathrm{~s}$. The identification of specific compounds was carried out by comparison of their spectra and retention time with those of standards.

All the individual phenolic compounds were confirmed by HPLC-DAD/ESI-MS as described in a previous paper [10].

\subsection{Culture Media and Growth Conditions}

Pediococcus pentosaceus $12 p$ was previously isolated from wines of Cafayate, Salta, Argentina [11]. The microorganism was grown in MRS medium supplemented with tomato juice $(15 \%) \mathrm{pH} 4.5$. The cells were washed 3 times with saline solution and inoculated in a synthetic-like wine medium $(\mathrm{SWM})$ that contained in $\mathrm{g} \mathrm{L}^{-1}$ : glucose 5.0; fructose 3.0, L-malic acid 3.0, tartaric acid 4.0; $\mathrm{K}_{2} \mathrm{SO}_{4}$ 0.1, $0.025 \mathrm{MgSO}_{4}, \mathrm{MnSO}_{4} 1.0$, YNB (Difco Yeast Nitrogen Base without amino acids and ammonium sulfate), 1.7\% (10X); $\mathrm{pH}$ was adjusted to 4.5. The medium was supplemented with $5 \%$ ethanol and the amino acids were required by the microorganism for growth as previously reported [12]. The complete composition of amino acids SWM medium is showed in Table 1. The medium was sterilized by filtration through a $0.22 \mu \mathrm{m}$ pore size nylon membrane.

\subsection{Antibacterial Activity Assay}

The antibacterial activity of the LMF of different wines was measured by determination of growth parameters of $P$. pentosaceus $12 \mathrm{p}$ in SWM (control medium) and in SWM supplemented with the LMF of "CS" and " $T$ " wines at different concentrations. The concentration of LMF of two varieties was adjusted at same concentration of natural wines $(1 \mathrm{X})$ and at four $(4 \mathrm{X})$ and eight (8X) times concentrated with respect to natural wines taking into account the total phenolic concentrations shown in Table 2. The bacterium was inoculated at level of $10^{7} \mathrm{CFU} \mathrm{mL} \mathrm{m}^{-1}$ and incubated for 
Table 1. Amino acid composition of SWM.

\begin{tabular}{|c|c|}
\hline Amino Acid & {$\left[g^{-1}\right]$} \\
\hline Asparagine & 0.200 \\
\hline Cysteine & 0.100 \\
\hline Glycine & 0.300 \\
\hline Histidine & 0.050 \\
\hline Isoleucine & 0.050 \\
\hline Methionine & 0.050 \\
\hline Phenylalanine & 0.040 \\
\hline Proline & 0.040 \\
\hline Serine & 0.100 \\
\hline Threonine & 0.050 \\
\hline Tryptophan & 0.050 \\
\hline Tyrosine & 0.004 \\
\hline
\end{tabular}

Table 2. Composition of the low molecular weight fraction isolated from Cabernet Sauvignon (LMF-CS) and Tannat (LMF-T) wines.

\begin{tabular}{|c|c|c|c|c|c|}
\hline Non-flavonoid Phenolics Compounds $\left[\mathrm{mg} \mathrm{L}^{-1}\right]$ & LMF-CS & LMF-T & Flavonoid Phenolics Compounds $\left[\mathrm{mg} \mathrm{L}^{-1}\right.$ ] & LMF-CS & LMF-T \\
\hline Hydroxybenzoic Acids/Derivatives & & & Flavanols & & \\
\hline Protocatechuic acid & $1.9 \pm 0.2$ & $3.4 \pm 0.4$ & (-)-Epicatechin & $13.6 \pm 0.8$ & $13.3 \pm 3.2$ \\
\hline Methyl gallate & $3.1 \pm 0.4$ & $8.7 \pm 0.6$ & Procyanidindimer 1 & $40.5 \pm 3.5$ & $86.0 \pm 4.4$ \\
\hline Total & $34.6 \pm 6.2$ & $54.4 \pm 3.7$ & Procyanidintrimer 2 & $4.4 \pm 0.5$ & $7.0 \pm 0.9$ \\
\hline Hydroxycinnamic acids/derivatives & & & Procyanidintrimer 3 & $8.5 \pm 0.7$ & $15.7 \pm 1.1$ \\
\hline trans-Caftaric acid & $7.1 \pm 1.5$ & $12.5 \pm 2.3$ & Procyanidintrimer 4 & nd & nd \\
\hline cis-Coutaric acid & $4.1 \pm 0.7$ & $7.3 \pm 1.5$ & Myricetin-3-glucoside & $5.0 \pm 0.5$ & $3.1 \pm 0.6$ \\
\hline trans-Caffeic acid & $2.2 \pm 0.04$ & $1.8 \pm 0.2$ & Quercetin-3-glucuronide & $10.4 \pm 0.8$ & $8.1 \pm 0.7$ \\
\hline trans-Fertaric acid & $2.3 \pm 0.3$ & $5.0 \pm 0.4$ & Quercetin-3-galactoside & $16.2 \pm 1.1$ & $12.2 \pm 0.4$ \\
\hline
\end{tabular}


Table 2. contd...

\begin{tabular}{|c|c|c|c|c|c|}
\hline Non-flavonoid Phenolics Compounds [ $\left.\mathrm{mg} \mathrm{L}^{-1}\right]$ & LMF-CS & LMF-T & Flavonoid Phenolics Compounds $\left[\mathrm{mg} \mathrm{L}^{-1}\right.$ ] & LMF-CS & LMF-T \\
\hline Hydroxybenzoic Acids/Derivatives & & & Flavanols & & \\
\hline trans-p-Coumaric acid & $4.4 \pm 0.5$ & $12.9 \pm 0.9$ & Quercetin-3-glucoside & $5.7 \pm 0.4$ & $5.7 \pm 0.4$ \\
\hline Total & $27.1 \pm 1.7$ & $43.1 \pm 1.8$ & Quercetin-3-rhamnoside & $2.2 \pm 0.4$ & $3.7 \pm 0.6$ \\
\hline Phenolics Alcohols & & & Isorhamnetin-3-galactoside & $8.6 \pm .1 .0$ & $9.1 \pm 1.3$ \\
\hline Tyrosol & $21.3 \pm 4.0$ & $15.2 \pm 1.7$ & Naringenin & $4.4 \pm 0.4$ & $10.0 \pm 1.0$ \\
\hline Stilbenes & & & Syringetin-3-glucoside & $2.2 \pm 0.2$ & $3.3 \pm 0.4$ \\
\hline trans-Resveratrol-3-glucoside & $1.7 \pm 0.1$ & $3.4 \pm 0.4$ & Total & $54.8 \pm 3.2$ & $55.2 \pm 3.1$ \\
\hline \multirow[t]{6}{*}{ Total non-flavonoids } & $84.7 \pm 4.1$ & $116.1 \pm 8.2$ & Dihydroflavonols & nd & nd \\
\hline & & & Dihydroquercetin-3-glucoside & nd & nd \\
\hline & & & Dihydroquercetin-3-rhamnoside & nd & nd \\
\hline & & & Dihydrokaempferol-3-glucoside & nd & nd \\
\hline & & & Total flavonoids & $144.8 \pm 12.0$ & $194.8 \pm 13.7$ \\
\hline & & & Total phenoliccompound & $229.4 \pm 14.1$ & $311.1 \pm 19.2$ \\
\hline
\end{tabular}

Values are expressed as mean \pm standard deviation; nd: not detected.

$96 \mathrm{~h}$ at $28^{\circ} \mathrm{C}$ under microaerophilic conditions. Before and after incubation, bacterial viability was determined by counting of viable cells in MRS-agar medium. These data were utilized to determine the growth rate $\left(\mu_{\max }\right)$ and the change in viability at the end of incubation (A) of the bacterium as follows:

$\mu_{\text {máx }}\left[\mathrm{h}^{-1}\right]=\left(\left(\log \mathrm{x} / \mathrm{x}_{\mathrm{o}}\right) /(\mathrm{t} x \log (2)\right.$

$A\left[\log C F U L^{-1}\right]=\log x-x_{0}$

Where,

$\mathrm{x}=$ viable cell concentration at the end of incubation time

$\mathrm{x}_{0}=$ initial viable cell concentration

\subsection{Transmission Electron Microscopy (TEM)}

An aliquot of samples obtained from each incubation condition of $P$. pentosaceus $12 \mathrm{p}$ in SWM with or without LMF supplementation were submitted to a TEM in order to evaluate, in a preliminary way, the mechanism for the antibacterial activity of LMF. The samples were fixed in Karnovsky's solution [13] and incubated overnight at $4^{\circ} \mathrm{C}$. The fixed samples were washed three times with the sodium phosphate buffer and then fixed with a 1:1 solution of sodium phosphate buffer / $2 \%$ osmium tetroxide $\left(\mathrm{OsO}_{4}\right)$. The samples were washed three times with distilled water and then a 1:1 solution of phosphate buffer/uranil acetate was added. After 30 min incubation in the dark, the solution was discarded and the samples were washed with ethanol $70 \%$, $90 \%$ and $100 \%$, and dehydrated with ethanol $100 \%$ and acetone. The bacterium was included in Spur resin, and heated at $60^{\circ} \mathrm{C}$ for $24 \mathrm{~h}$. Ultrathin sections were made with an ultramicrotome, mounted in copper grids and contrasted with uranil acetate and lead citrate [14]. The samples were observed with a Zeiss EM109 (Carl Zeiss NTS GmbH, Oberkochen, Germany) transmission electron microscope.

\subsection{Free Radical Scavenging Ability}

The free radical scavenging ability was quantified by the scavenge capacity of samples against DPPH (2,2-diphenyl-1picrylhydrazyl), a stable free radical with the method proposed by Von Gadow, Joubert and Hansmann [17]. Ascorbic acid solution was used as a positive control. Absorbance was measured in a microplate reader at $517 \mathrm{~nm}$. Results are expressed as a percentage of radical scavenging of samples.

\subsection{Ferric Reducing Antioxidant Power (FRAP) Assay}

Antioxidant activity was measured by the reduction of colorless ferric tripiridyltriazine (Fe III) complex to colored $\mathrm{Fe}(\mathrm{II})$-tripyridyltriazine complex due to the action of electron-donating antioxidants present in samples [16]. The measurement of absorbance was performed at $593 \mathrm{~nm}$ in a microplate reader. A standard curve was constructed using $\mathrm{Fe}(\mathrm{II})$ sulfate solution $(100-3,500 \mu \mathrm{M})$. Results are expressed in $\mu \mathrm{mol} \mathrm{FeSO}_{4} \mathrm{~L}^{-1}$.

\subsection{Angiotensin I-converting Enzyme Inhibition (ACEI) Activity}

The ACEI activity was determined by the method described by Cushman and Cheung [15] based in the quantification of hippuric acid formed by the reaction of hippuryl-histidyl-leucine with angiotensin I-converting enzyme (ACE) in the presence and absence of an inhibitor (samples). Absorbance was measured at $228 \mathrm{~nm}$ and activity is expressed as the percentage of ACE inhibition. 
Table 3. Effect of the low molecular weight fraction of phenolic compounds from Cabernet Sauvignon (LMF-CS) and Tannat (LMF-T) wines on the growth parameters of $P$. pentosaceus $12 \mathrm{p}$.

\begin{tabular}{|c|c|c|c|c|c|c|c|}
\hline & Control & \multicolumn{3}{|c|}{ LMF-CS } & \multicolumn{3}{|c|}{ LMF-T } \\
\hline & & $\mathbf{1 X}$ & $\mathbf{4 X}$ & $\mathbf{8 X}$ & $\mathbf{1 X}$ & $\mathbf{4 X}$ & $\mathbf{8 X}$ \\
\hline \hline$\mu \max \left[\mathrm{h}^{-1}\right]$ & $0.019 \pm 0.002$ & $0.005 \pm 0.003$ & $-0.016 \pm 0.001$ & $-0.230 \pm 0.001$ & $0.005 \pm 0.004$ & $-0.220 \pm 0.002$ & $-0.230 \pm 0.002$ \\
\hline $\mathrm{A}\left[\log \mathrm{CFU} \mathrm{mL} \mathrm{m}^{-1}\right]$ & $1.06 \pm 0.11$ & $0.75 \pm 0.09$ & $-4.64 \pm 0.32$ & $-6.72 \pm 0.56$ & $0.64 \pm 0.36$ & $-6.46 \pm 0.43$ & $-6.61 \pm 0.46$ \\
\hline
\end{tabular}

Values are expressed a mean \pm standard deviation

\section{RESULTS}

\subsection{Quantification of Low Molecular Weight Phenolic Compounds}

Table 2 shows the concentrations of low molecular weight phenolic compounds present in the LMF in the two red wines analyzed. Phenolic compounds were grouped into non-flavonoids (hydroxybenzoic and hydroxycinnamic acids and their derivatives, stilbenes and phenolic alcohols) and flavonoids (flavanols, flavonols and dihydroflavonols).

The total flavonoid compounds content of LMF-CS and LMF-T were higher in $70.9 \%$ and $56.7 \%$ respectively compared with the non-flavonoids content of both wines. Concerning non-flavonoids concentration, the hydroxybenzoic acids/derivatives concentration were the most abundant compounds in LMF-CS and LMF-T, representing the $15.1 \%$ and $18.2 \%$ of total phenolics quantified respectively. Gallic acid showed the highest concentration in both studied LMF, being higher in $51.9 \%$ in LMF-T than that detected in LMF-CS.

The concentration of the hydroxycinnamic acids/derivatives, represents the $11.8 \%$ and $14.5 \%$ of total phenolics quantified in LMF-CS and LMF-T respectively. Among these compounds, the concentration of trans-caftaric acid, cis-coutaric acid and trans-p-coumaric acid were respectively higher in $76.0 \%, 78 \%$ and $193.2 \%$ in the LMF$\mathrm{T}$ with respect to $\mathrm{LMF}-\mathrm{CS}$. Among stilbenes, the non flavonoids compounds were generally related to nutraceutical properties [16], trans-resveratrol-3-glucoside were detected in both LMF studied, being this compound bring higher in $100.0 \%$ in LMF-T with respect to LMF-CS. Among flavonoids phenolics compounds, flavanols are the major class of phenolic compounds present in the LMF-CS and LMF-T representing the $39.2 \%$ and $44.8 \%$ of total phenolics quantified respectively. Relating to flavonols, compounds with great relevance because their health properties and the contribution to colour of wine by the copigmentation phenomenon [17], were found in form of glycosides, principally quercetin-3-galactoside, quercetin-3glucuronide, isorhamnetin-3-galactoside, quercetin-3glucoside and myricetin-3-glucoside. In a lower ratio naringenin and syringetin were detected.

\subsection{Inhibitory Effects of Low Molecular Weight Fraction of Phenolic Compounds (LMF) of Wine}

$P$. pentosaceus $12 \mathrm{p}$ at $96 \mathrm{~h}$ incubation in SWM (control) grow with $\mu_{\max }$ of $0.019 \mathrm{~h}^{-1}$, increasing the viable cell concentration from 7.79 to $8.85 \mathrm{Log}_{\mathrm{CFU} \mathrm{mL}}^{-1}$ (Table 3).
The supplementation of SWM with LMF-CS and LMF-T at a same concentration of wine (1X), produces a reduction of "A" by 0.31 and 0.42 units. In both conditions, the $\mu_{\max }$ decreases to $0.005 \mathrm{~h}^{-1}$. The supplementation with LMF-CS and LMF-T four or eight times concentrated (4X and $8 X$ ), produced the death of the microorganism in the SWM, evidenced by the negative values of growth rate $\left(\mu_{\max }\right)$ and the decrease in the viability change parameter (A). The supplementation with LMF-T four times concentrated produces higher inhibitory effect on microbial growth with respect to LMF-CS at the same concentration, evidenced by the higher reduction in viable cells as showed in Table $\mathbf{3}$.

\subsection{Microscopy Study}

The scanning electron microscopy technique was utilized in order to demonstrate that the inhibitory effects of LMF of wines are linked to a possible change in cell morphology (Fig. 1). After incubation of P. pentosaceus $12 \mathrm{p}$ in control medium (SWM), no changes in the membrane integrity was observed (Fig. 1-A $\mathbf{A}_{1}$ ). Identical results were observed in the presence of the LMF of both wines as a single concentration (Fig. 1-A2). The micrographs "B" to "C" displayed in (Fig. 1) shows that the supplementation of SWM with the LMF of both wines, four and eight times concentrated, produces a breakdown of the cell membrane and the subsequent release of the cytoplasm material.

\subsection{Antioxidant and Scavenging Activities}

The LMF isolated from wines showed high antioxidant capacities, as indicated by the DPPH and FRAP results (Fig. 2a, b). The DPPH radical scavenging rate ranged around $20 \%$ in SWM supplemented with LMF at the same wine concentration, regardless of wine variety utilized. The increase in the concentration of LMF-CS four and eight times in SWM enables the increase in DPPH scavenging by $21.4 \%$ and $80.6 \%$, respectively. The values for this activity obtained in SWM supplemented with LMF-T are in the same order than that detected in SMW plus LMF-CS at the same studied concentrations.

In SWM supplemented with LMF-CS and LMF-T at the same wine concentration (1X), the FRAP activity detected was 6116.0 and $5548.7 \mu \mathrm{mol} \mathrm{L}{ }^{-1}$ of $\mathrm{FeSO}_{4}$, respectively. A significant increase in FRAP activity was detected in SWM with the increase of LMF concentration, reaching 15125.0 and $47668.8 \mu \mathrm{mol} \mathrm{L}^{-1}$ of $\mathrm{FeSO}_{4}$ in $\mathrm{SWM}$ supplemented with LMF-CS four and eight times concentrated, respectively. At this condition, in the SWM plus LMF-T, the FRAP activity is in the same order than that detected in SWM plus LMF-CS. 


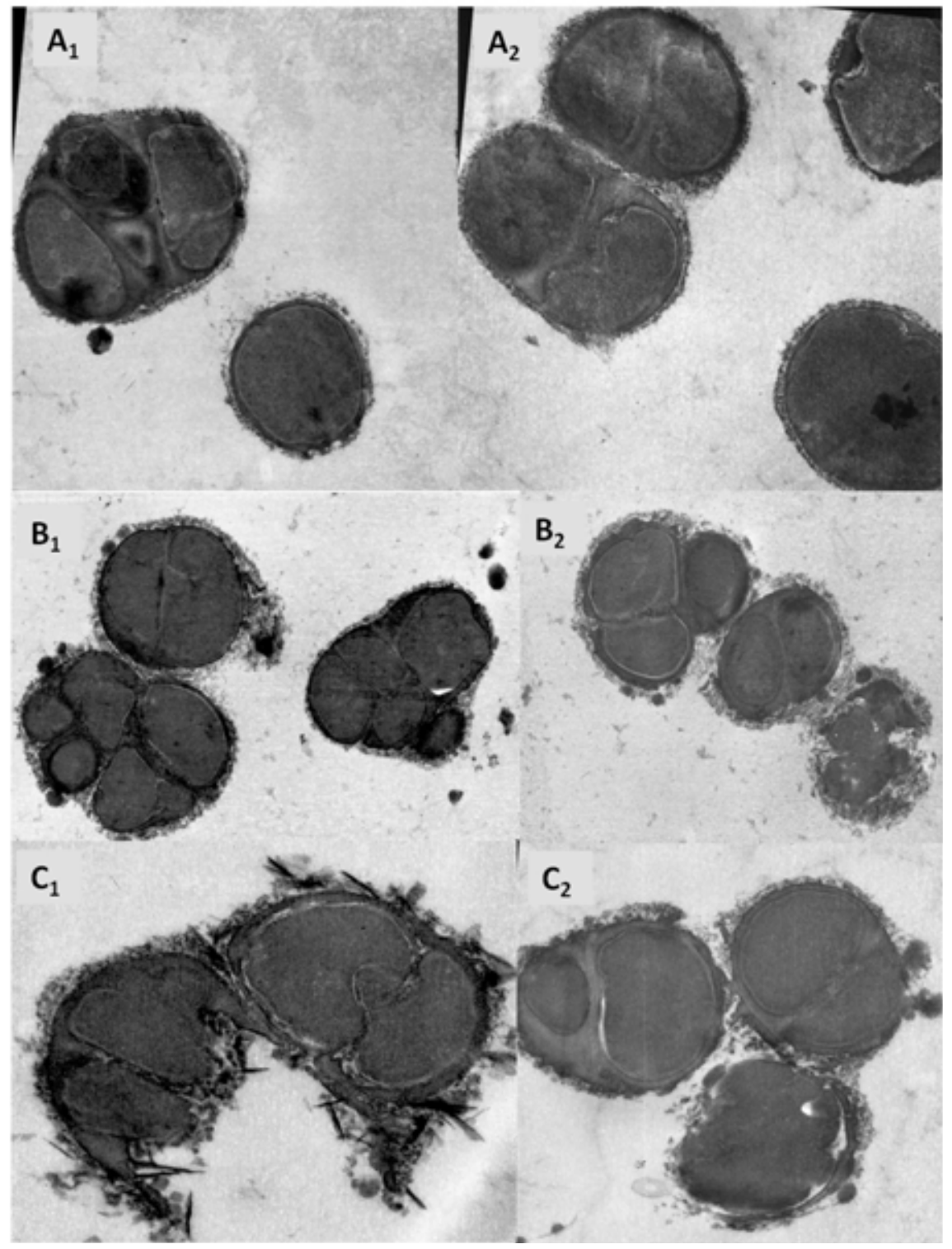

Fig. (1). Electron micrographs of ultrathin sections of $P$. pentosaceus $12 \mathrm{p}$ after $96 \mathrm{~h}$ incubation in Synthetic like-wine medium (SWM)(A $\left.\mathrm{A}_{1}\right)$; and SWM supplemented with the fraction of phenolic compounds of low molecular weight from Cabernet Sauvignon (LMF-CS) or Tannat (LMF-T) at the same wine concentration (1X) and four (4X) or eight (8X) times concentrated, as follow: $\mathrm{A}_{2}$ : LMF-CS or LMF-T (1X); $\mathrm{B}_{1}$ : LMF-CS (4X); $\mathrm{B}_{2}$ : LMF-CS (8X); $\mathrm{C}_{1}$ : LMF-T (4X) and $\mathrm{C}_{2}$ : LMF-T (8X).
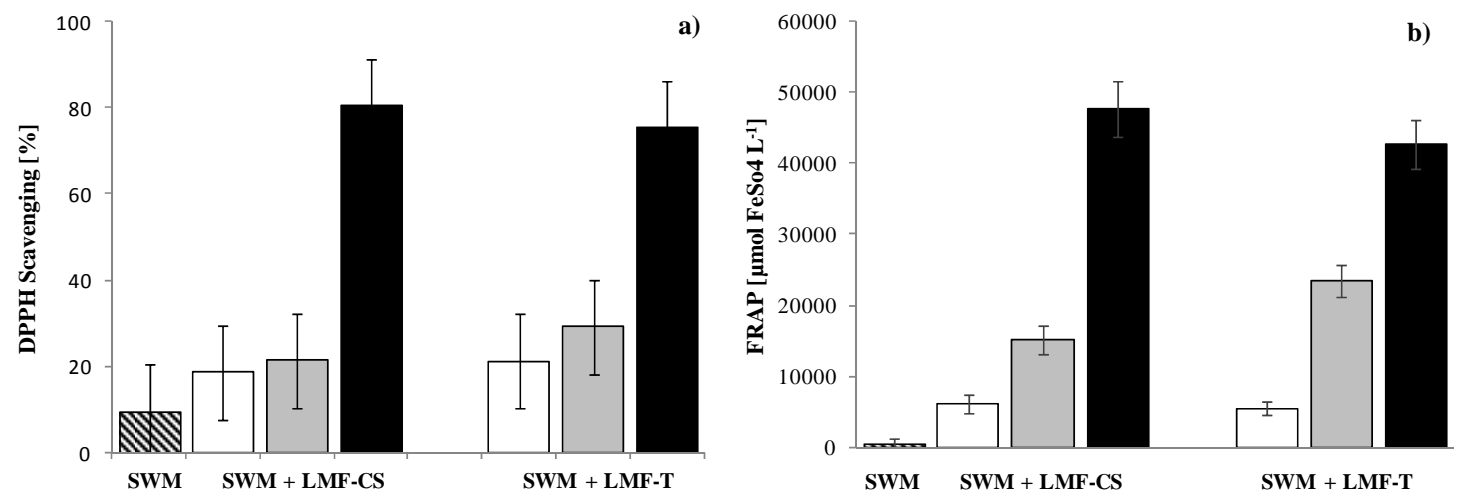

Fig. (2). DPPH scavenging ability a) and Ferric Reducing Antioxidant Power b) in synthetic-like wine medium (SWM) (hatched bars) and SWM supplemented with the fraction of phenolic compounds of low molecular weight from Cabernet Sauvignon (LMF-CS) or Tannat (LMF$\mathrm{T})$ at the same wine concentration (1X) (white bars), four times concentrated (gray bars) (4X) and eight times concentrated (8X) (black bars). 


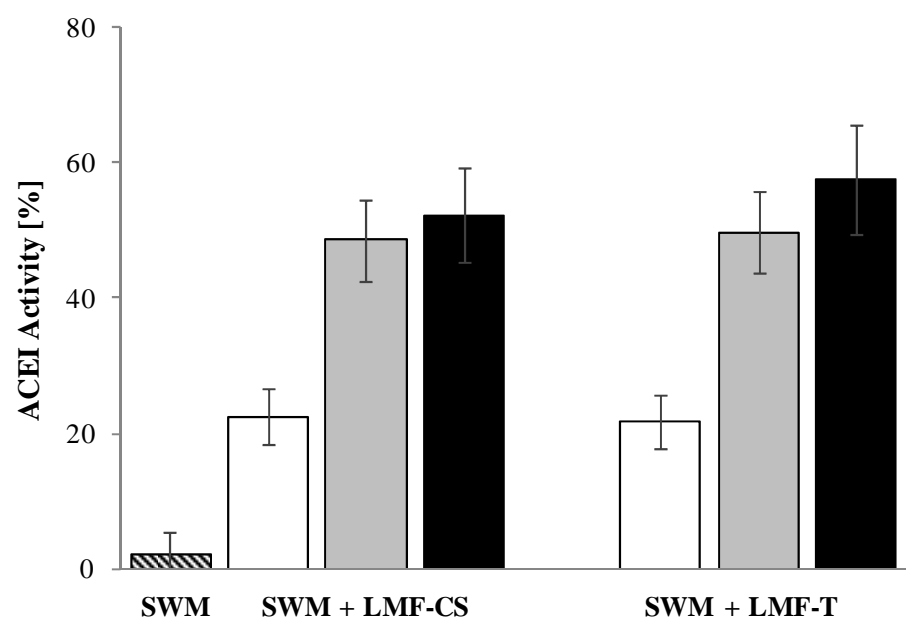

Fig. (3). ACEI activity [\%] in synthetic-like wine medium (SWM) (hatched bars) and SWM supplemented with the fraction of phenolic compounds of low molecular weight from Cabernet Sauvignon (LMF-CS) or Tannat (LMF-T) at the same wine concentration (1X) (white bars), four times concentrated (gray bars) (4X) and eight times concentrated ( $8 \mathrm{X})$ (black bars).

\subsection{Antihypertensive Activity}

The modifications of biological activities in the SWM due to the incorporation of LMF of studied wines are showed in (Fig. 3). In control medium (SWM), the ACEI activity was non-detectable. In the SWM, the supplementation with the LMF-CS and LMF-T at the same wine concentration (1X) produces an increase by $22.0 \%$ and $23.2 \%$ of ACEI activity, respectively. The ACEI activity increased reaching $48.6 \%$ and $49.7 \%$ in SWM supplemented with LMF-CS and LMF-T four times concentrated, respectively. In the SWM supplemented with LMF-CS or LMF-T eight times concentrated, the ACEI activity are in the same order than that detected in SWM supplemented with LMF at concentration $4 \mathrm{X}$.

\section{DISCUSSION}

This study reports new knowledge about the inactivation of $P$. pentosaceus $12 \mathrm{p}$, strain that may affect wine organoleptic properties during winemaking, by low molecular weight phenolic compounds present in Argentinean wines. The development of new alternatives to the use of sulphites in enology is a current topic of great interest. Besides, the content of phenolic compounds of low molecular weight of Cafayate wines has been characterized for the first time in this study. Regarding the phenolic composition, flavonoid compounds were the most abundant fraction compared with non-flavonoids in the two varieties examined, as well as others reported by others authors [10, 18, 19]. The concentrations of hydroxibenzoic and hydroxycinnamic acids detected are in agreement with the values reported by other authors for the same wine varieties [10]. The concentrations of these compounds are in larger extent in LMF-T with respect to LMF-CS, mainly gallic acid, ethyl gallate, trans-caftaric and trans-p-coumaric acids. Data published by other authors shows that the phenolic compounds with largest growth inhibitory activity against $\mathrm{LAB}$ from wine are the hydroxibenzoic and hydroxycinnamic acids $[5,7,20]$.
In our experiments, the bacterium was cultivated in synthetic-like wine medium (SWM) ethanol-containing in order to simulate the wine environment. In this conditions, the supplementation with the LMF at same concentration of wines produce a slight diminution in growth parameters of the bacterium. When the concentration of LMF of both wines increase four times in the SWM, the growth parameters were reduced dramatically. When the concentration of the assayed LMF was adjusted at $4 \mathrm{X}$ in SWM, only the presence of LMF-T produced the total loss of bacterium viability. This behavior could be explained by the higher concentration of phenolic compounds of LMF-T with respect to LMF-CS. The studies conducted to date about the inhibitory activity of wine phenolics compounds against $\mathrm{LAB}$ were performed utilizing the pure compounds in different growth conditions $[6,7,20]$. In this study the fraction of low molecular weight of wine that contains a complex mixture of pure compounds in different concentrations were for the first time utilized to carry out antibacterial experiments. From the results of antibacterial activity assay and electron microscopy is possible to conclude that, the inhibitory effect of phenolic fraction (LMF) at identical wine concentrations against $P$. pentosaceus, is not linked to an alteration of cell membrane in the assayed experimental conditions. On the other hand, when the concentration of phenolic compounds were adjusted at a concentration four and eight times higher than wine, it is possible to infer that the inhibitory activity could be associated, at least to a breakdown of the cell membrane, as showed in the electronic micrographs.

The study of the mechanisms by which polyphenols inhibit the growth of LAB are in the first stages nowadays, however several authors have reported that polyphenols alter the cell membrane structure producing leakage of intracellular constituents [21,22] as well as enhanced the proton influx and the potassium and phosphate efflux [20] by hydroxycinnamic and hydroxybenzoic acids in Oenococcus oeni and Lactobacillus hilgardii suspensions. Other authors have demonstrated that the incubation of $P$. pentosaceus and 
O. oeni with kaempferol, ethyl gallate, ferulic acid and transresveratrol produced a breakdown of the cell membrane and the subsequent release of cytoplasm material into the medium $[6,7]$.

In this study, the phenolic fraction obtained from Tannat wines at a total concentration of $1192.4 \mathrm{mg} \mathrm{L}^{-1}$ in SWM (4X), enables the total death of viable cells of $P$. pentosaceus $12 \mathrm{p}$. This result is of great interest since, as reported by others authors, the effective concentration of pure phenolic compounds that produce the total inhibition of LAB are significantly higher than that reported in this study [23].

Other authors have reported that phenolic compounds alone at concentrations found that wine did not produce inhibitory effect on LAB growth [6]. In this study, a synergistic inhibitory effect of wine phenolic compounds contained in both LMF against $P$. pentosaceus $12 \mathrm{p}$ was observed at the natural wine concentration, being $230 \mathrm{mg} \mathrm{L}^{-1}$ for LMF-CS and $300 \mathrm{mg} \mathrm{L}^{-1}$ for LMF-T. The synergistic inhibitory activity increases significantly when the concentration of phenolic compounds increases four times, reaching $917.6 \mathrm{mg} \mathrm{L}^{-1}$ for LMF-CS and $1192.4 \mathrm{mg} \mathrm{L}^{-1}$ for LMF-T. These results are in agreement with the hypothesis of García Ruiz, Bartolomé, Cuevas, Martín Alvarez and Moreno-Arribas [6], that have postulated that a synergistic effect of wine phenolic compounds could be observed at concentration of $900-1400 \mathrm{mg} \mathrm{L}^{-1}$ for young red wines and may promote inactivation of $\mathrm{LAB}$ in the wine environment.

The LMF of both wines analyzed in this study have high antioxidant, radical scavenging and antihypertensive activity. These beneficial properties for human health will have to be also considered as additional values of the phenolic compounds whether they are used as antimicrobial additives in enology. As expected, the increase in phenolic compounds concentration of LMF-CS and LMF-T in SWM is correlated with the increase in FRAP and DPPH activity. With respect to antihypertensive activity, the maximum ACE inhibition was detected in SWM supplemented with the LMF four times concentrated of both wines. The composition of LMFCS and LMF-T include flavanols and procyanidins to a greater extent. These compounds are previously reported as the phenolic compounds that competitively inhibit ACE activity $[24,25]$. It is important to note that the antihypertensive activity of the phenolic compounds may be added to the same activity of the peptides present in the wine $[12,26-28]$ which may result in a synergistic effect of two molecules of different kinds.

Phenolic compounds could be introduced as a "natural antimicrobial agents" for the use in winemaking, representing a natural alternative to consider for the completely or at least partially replacement of the use of sulphites in enology. The use of sulphites as additive is strictly controlled, since it may cause undesirable organoleptic alterations and especially, their consumption could represent a risk to human health [5]. In addition, as reported by other authors [6, 29], the use of sulphites at suggested concentrations in enology, does not lead to cell membrane lysis of bacteria but affects cell viability, indeed the cells entering in a viable but non-culturable state, retaining their metabolic activity. The results obtained in this work suggested that the phenolic compounds inactivate the bacteria and also lead to their death by breakdown of the cellular membrane. In conclusion, the use of phenolic compounds as potential antimicrobial agents could represent an effective alternative to the use of sulphites in enology against spoilage bacteria, enabling the reduction or elimination of toxicity produced by sulphites and adding to wines beneficial properties to human health. At present, ongoing experiments with phenolic fractions of different wines, alone or supplemented with pure phenolic compounds, are being carried out in order to establish the better associations and/or conditions to inactivate effectively different wine spoilage bacteria under wine laboratory conditions.

\section{CONFLICT OF INTEREST}

The authors confirm that this article content has no conflict of interest.

\section{ACKNOWLEDGEMENTS}

The authors wish to thank to Agencia Nacional de Promoción Científica y Técnica and Consejo Nacional de Investigaciones Científicas y Técnicas (CONICET).

\section{REFERENCES}

[1] Manach, C.; Scalbert, A.; Morand, C.; Rémés, C.; Jiménez, L. Polyphenols: food sources and bioavailability. Am. J. Clin. Nutr., 2004, 86, 727-747.

[2] Xia, E.Q.; Deng, G.F.; Guo, Y.J.; Li, H.B. Biological activities of poly phenols from grapes. Int. J. mol. Sci., 2010, 11, 622-646.

[3] Dimitrios, B. Sources of natural phenolic antioxidants. Trends Food Sci. Tech., 2006, 17, 505-512.

[4] Kapur, C.; Kapoor, H.C. Antioxidants in fruits and vegetables the millenium's health. Int. J. Food Sci. Tech., 2001, 36, 703-725.

[5] García-Ruiz, A.; Bartolomé, B.; Martínez-Rodríguez, A.J.; Pueyo, E.; Martín Álvarez, P.J.; Moreno-Arribas, M.V. Potential of phenolic compounds for controlling lactic acid bacteria growth in wine. Food Control, 2008, 19, 835-841.

[6] García-Ruiz, A.; Bartolomé, B.; Cueva, C.; Martín-Álvarez, P.J.; Moreno-Arribas, M.V. (2009). Inactivation of oenological lactic acid bacteria (Lactobacillus hilgardii and Pediococcus pentosaceus) by wine phenolic compounds. J. Appl. Microbiol., 2009, 107, 1042-1053.

[7] García-Ruiz, A.; Moreno-Arribas, M.V.; Martín-Álvarez, P.J.; Bartolomé, B. Comparative study of the inhibitory effects of wine poly phenols on the growth of enological lactic acid bacteria. Int. J. Food Microbiol., 2011,145,426-431.

[8] Andriambeloson, E.; Magnier, C.; Haan-Archipoff, G.; Lobstein, A., Anton R.; Beretz, A. Natural dietary polyphenolic compounds cause endothelium-dependent vasorelaxation in rat thoracic aorta J. Nutr., 1998, 12, 2324-2333.

[9] Ghiselli, A.; Nardini, M.; Baldi, A.; Scaccini, C. Antioxidant activity of different phenolic fractions separated from an Italian red wine. J. Agr. Food Chem., 1998, 46, 361-367.

[10] Fanzone, M.; Zamora, F.; Jofré, V.; Assof, M.; Gómez Cordovés, C.; Peña Neira, A. Phenolic characterisation of red wines from different grape varieties cultivated in Mendoza province (Argentina). J. Sci. Food Agric., 2011, 24, 154-159.

[11] Strasser de Saad, A.M.; Manca de Nadra, M.C. Isolation and identification of the lactic acid bacteria from Cafayate (Argentina) wines. Microbiol. Aliments Nutr., 1987, 5, 45-49.

[12] Aredes Fernández, P.A.; Stivala, M.G.; Rodríguez Vaquero, M.J.; Farías M.E. Increase in antioxidant and antihypertensive activity by Oenococcus oeni in a yeast autolysis wine model. Biotechnol. Lett., 2011, 33, 359-364.

[13] Karnovsky, M. J. A formaldehyde glutaraldehyde fixative of high osmolality for use in electron microscopy. J. Cell Biol., 1965, 27, 137-138. 
[14] Venable, J.R; Coggeshall, R. A simplified lead-citrate stain for use in electron microscopy. J Cell. Biol., 1965, 25, 407-408.

[15] Cushman, D.W.; Cheung, H.S. Spectrophotometric assay and propertiesof the angiotensin I-converting enzyme of rabbit lung. Biochem. Pharmacol., 1971, 20, 1637-1648.

[16] Benzie, I.F.F.; Strain, J.J. The ferric reducing ability of plasma (FRAP) as measure of antioxidant power the FRAP assay. Analytical Biochem., 1996, 239, 70-76.

[17] Von Gadow, A.; Joubert, E.; Hansmann, C.F. Comparison of antioxidant activity of aspalathin with that of other plant phenols of Rooibosed tea (Aspalathonlinearis),-tocopherol, BHT, and BHA. $J$. Agr. Food Chem., 1997, 45, 632-638.

[18] Fanzone, M.; Pena-Neira, A.; Jofre, V.; Assof, M.; Zamora, F. Phenolic characterization of Malbec wines from Mendoza province (Argentina). J. Agric. Food Chem., 2010, 58, 2388-2397.

[19] Monagas, M.; Suarez, R.; Gómez-Cordovés, C.; Bartolomé, B. Simultaneous determination of nonanthocyanin phenolic compounds in red wines by HPLC-DAD/ESI-MS. Am. J. Enol. Vitic., 2005, 56, 139-147

[20] Campos, F.M.; Couto, J.A.; Figueiredo, A.R.; Tóth, I.V.; Rangel, A.O.S.S.; Hogg, T.A. Cell membrane damage induced by phenolic acids on wine lactic acid bacteria. Int. J. Food Microbiol., 2009, $135,144-151$

[21] Johnston, M.D.; Hanlon, G.W.; Denyer, S.P.; Lambert, R.J.W.. Membrane damage to bacteria caused by single and combined biocides. J. Appl. Microbiol., 2003, 94, 1015-1023.

[22] Rodríguez, H.; Curiel, J.A.; Landete, J.M.; de las Rivas, B.; de Felipe, F.L.; Gómez-Cordovés, C.; Mancheño, J.M.; Muñoz, R.
Foodphenolics and lacticacid bacteria. Int. J. Food Microbiol., 2009, 132, 79-90.

[23] Landete, J.M.; Rodríguez, H.; De Las Rivas, B;.Muñoz, R. Highadded-value antioxidants obtained from thedegradation of wine phenolics by Lactobacillus plantarum. J. Food Prot., 2007, 70, 2670-2675.

[24] Actis-Goretta, L.; Ottaviani, J.I.; Keen, C.L.; Fraga, C.G. Inhibition of angiotensin converting enzyme (ACE) activity by flavan-3-ols and procyanidins. FEBS Lett., 2003, 555, 597-600.

[25] Actis-Goretta, L.; Ottaviani, J.I.; Fraga C.G. Inhibition of Angiotensin Converting Enzyme Activity by Flavanol-Rich Foods. J. Agric. Food Chem., 2006, 54, 229-234.

[26] Pozo-Bayon, M.A.; Alcaide, J.M.; Polo, M.C.; Pueyo, E. Angiotensin I-converting enzyme inhibitory compounds in white and red wines. Food Chem., 2007, 10, 43-47.

[27] Apud, G.R.; Rodríguez Vaquero, M.J.; Rollan, G.; Stivala, M.G.; Aredes Fernández, P.A. Increase in antioxidant and antihypertensive peptides from Argentinean wines by Oenococcus oeni. Int. J. Food Microbiol, 2013, 163, 166-170.

[28] Apud, G.R.; Stivala, M.G., Aredes Fernandez, P; Rodriguez Vaquero M.J. Proteolytic activity of Oenococcus oeni enables the increase in antioxidant and antihypertensive activities from wine. Curr. Pharm. Biotech., 2013, 14, 809-813.

[29] Millet, V.; Lonvaud-Funel, A. The viable but non cultivable state of wine micro-organisms during storage. Lett. Appl. Microbiol., 2000, 30, 136-141.

(C) Stivala et al.; Licensee Bentham Open.

This is an open access article licensed under the terms of the Creative Commons Attribution Non-Commercial License (http://creativecommons.org/licenses/bync/3.0/), which permits unrestricted, non-commercial use, distribution and reproduction in any medium, provided the work is properly cited. 